\title{
Patient selection for anti-PD-1/PD-L1 therapy in advanced non-small-cell lung cancer: implications for clinical practice
}

\author{
Raffaele Califano*,1,2,3, Rohit Lal ${ }^{4}$, Conrad Lewanski ${ }^{5}$, Marianne C Nicolson ${ }^{6}$, Christian H \\ Ottensmeier ${ }^{7}$, Sanjay Popat ${ }^{8}$, Matthew Hodgson ${ }^{9}$ \& Pieter E Postmus ${ }^{10}$ \\ ${ }^{1}$ Department of Medical Oncology, The Christie NHS Foundation Trust, Manchester, UK \\ ${ }^{2}$ Department of Medical Oncology, Manchester University NHS Foundation Trust, Manchester, UK \\ ${ }^{3}$ Division of Cancer Sciences, University of Manchester, Manchester, UK \\ ${ }^{4}$ Lung Cancer Unit, Guy's \& St Thomas' Hospital, London, UK \\ ${ }^{5}$ Department of Oncology, Charing Cross Hospital, London, UK \\ ${ }^{6}$ Department of Oncology, Aberdeen Royal Infirmary, Scotland, UK \\ ${ }^{7}$ Cancer Sciences Unit, Faculty of Medicine, University of Southampton \& University Hospital Southampton NHS Foundation Trust, \\ Southampton, UK \\ ${ }^{8}$ Royal Marsden Hospital \& the National Heart \& Lung Institute, Imperial College London, London, UK \\ ${ }^{9}$ Roche Products Ltd, Welwyn Garden City, UK \\ ${ }^{10}$ Clatterbridge Cancer Centre, Liverpool Heart \& Chest Hospital, University of Liverpool, Liverpool, UK \\ *Author for correspondence: Tel.: +44 (0)161 4463745; raffaele.califano@christie.nhs.uk
}

Immune checkpoint inhibitors targeting PD-1 or PD-L1 represent a standard treatment option for patients with advanced non-small-cell lung cancer. However, a substantial proportion of patients will not benefit from these treatments, and robust biomarkers are required to help clinicians select patients who are most likely to benefit. Here, we discuss the available evidence on the utility of clinical characteristics in the selection of patients with advanced non-small-cell lung cancer as potential candidates for single-agent anti-PD-1/PD-L1 therapy, and provide practical guidance to clinicians on identifying those patients who are most likely to benefit. Recommendations on the use of immune checkpoint inhibitor in clinically challenging populations are also provided.

First draft submitted: 26 April 2018; Accepted for publication: 11 June 2018; Published online: 6 July 2018

Keywords: atezolizumab $\bullet$ immune checkpoint blockade $\bullet$ nivolumab $\bullet$ non-small-cell lung cancer $\bullet$ patient selection - pembrolizumab

Immune checkpoint inhibitors (ICIs) blocking the PD-1/PD-L1 pathway, such as nivolumab, pembrolizumab and atezolizumab, represent a standard treatment option for patients with advanced non-small-cell lung cancer (NSCLC) [1], and have rapidly been adopted into clinical practice [2,3]. However, with a response rate of 14-23\% in unselected populations and 16-48\% in patients with PD-L1-expressing tumors [4], these drugs offer improved outcomes in some patients, but not all. Currently, there remains uncertainty about which patients with NSCLC are most likely to benefit from anti-PD-1/PD-L1 therapy. Robust predictive markers are urgently required to identify these patients to ensure they receive the most appropriate treatment.

PD-L1 expression has been proposed as a potential biomarker of response to ICI in NSCLC as there is evidence suggesting increased response rates and longer overall survival (OS) in patients with higher PD-L1 expression [5]. However, not all studies support this, and durable responses have been observed in patients with low or no PD-L1 expression [6,7]. This may be explained, at least in part, by the dynamic and heterogeneous nature of PD-L1 expression, which may lead to misclassification of PD-L1 status [8-10]. Rebiopsy may therefore be a worthwhile option in patients who do not respond to first-line treatment and who initially test negative for PD-L1 expression, providing that a different PD-L1 result may change their clinical options.

There are several other limitations of PD-L1 expression as a biomarker. Anti-PD-1/PD-L1 drugs do not inhibit every co-inhibitory interaction that may play a role in antitumor T-cell responses; a fact that may contribute to

Future Medicine 
the failure of PD-L1 expression to fully differentiate responders and nonresponders. Furthermore, each anti-PD1/PD-L1 drug has been co-developed with its own PD-L1 immunohistochemistry (IHC) diagnostic assay [11]. Each assay uses different antibody clones for PD-L1 detection with different affinities, specificities and thresholds for clinical decision-making $[11,12]$. Results also require subjective interpretation by a pathologist [11,13]. According to the US FDA, pembrolizumab must be used in conjunction with its companion PD-L1 test, while the assays for nivolumab and atezolizumab are considered complementary and their use is not mandatory [12,14]. Of note, in a post hoc analysis of OAK, a Phase III trial that compared atezolizumab with docetaxel in pretreated patients with advanced NSCLC, PD-L1 expression in a subset of patients was determined using two diagnostic IHC assays. The patients were classified according to atezolizumab's complementary assay (SP142) and pembrolizumab's companion assay (22C3) to see what impact this had on study outcomes. Irrespective of the assay used, atezolizumab was shown to improve survival in patients with PD-L1-negative tumors, confirming the original findings of the trial [15]. Other studies have demonstrated high concordance between most PD-L1 IHC assays, but have not correlated these data with clinical results [16-18]. Efforts are underway by the pharmaceutical industry and regulators to harmonize these diagnostic tests. Blueprint is one such project, aiming to understand the similarities and differences between the testing systems $[19,20]$. The recently completed second phase of Blueprint compared five PD-L1 detection assays including the new assay for avelumab (Dako 73-10), which was found to stain a slightly higher percentage of tumor cells than other assays [21]. Phase II demonstrated the utility of training platforms for standardizing scoring among pathologists and showed that there was a good correlation of PD-L1 expression between tumor and cytology specimens [19,21], a finding supported by other recent studies [22,23].

Tumor mutational burden (TMB) is a key emerging biomarker of response to PD-1 and PD-L1 inhibitors that has shown promise across cancer types [24]. Using whole-exome sequencing, a higher nonsynonymous mutation burden was shown to be associated with significantly improved objective response rate, durable clinical benefit and progression-free survival (PFS) in NSCLC patients treated with pembrolizumab compared with those with a lower burden [25]. Efficacy also correlated with a higher neoantigen burden [25], and it has been proposed that higher levels of neoantigens formed from nonsynonymous mutations enhance tumor antigenicity and trigger an immune response within the tumor once the inhibition of the PD-1 pathway is prevented by immunotherapy [25-27]. An exploratory analysis from CheckMate 026 revealed that among patients with high TMB, nivolumab was associated with a longer median PFS versus chemotherapy (9.7 vs 5.8 months; hazard ratio [HR]: 0.62; 95\% CI: 0.38-1.00). In patients with low/medium TMB, PFS was shorter in the nivolumab arm (4.1 vs 6.9 months; HR: 1.82, 95\% CI: 1.30-2.55), while OS was similar between treatment groups regardless of TMB [28]. Similarly, Gettinger and colleagues demonstrated that increased somatic mutations and neoantigens were significantly associated with an increased response to anti-PD-1 inhibitors but not with OS at 3 years [29]. An association between TMB and response to atezolizumab has also been demonstrated both in unselected and PD-L1-selected populations, and in first-line and second-line settings [30]. TMB can be determined using clinically accessible techniques, such as targeted next-generation sequencing and comprehensive gene panels [26,30], and from circulating tumor DNA using a blood-based assay [31]. Rizvi et al. demonstrated that quantification of TMB by targeted next-generation sequencing correlated well with whole-exome sequencing and that TMB was greater in patients with durable clinical benefit than those without. Furthermore, combining TMB with PD-L1 expression provided greater predictive power and further enriched for benefit to anti-PD-1/PD-L1 therapy [32]. The recently reported CheckMate 227 trial showed that chemotherapy-naive patients with advanced NSCLC and a high TMB ( $\geq 10$ mutations/Mb) treated with nivolumab plus ipilimumab experienced a longer PFS than the group treated with chemotherapy (7.2 vs 5.5 months; HR: 0.58, 97.5\% CI: 0.41-0.81; p < 0.001). The 1-year PFS rate ( 42.6 vs $13.2 \%)$ and objective response rate ( 45.3 vs $26.9 \%$ ) were also higher in the nivolumab plus ipilimumab arm [33]. At present TMB remains investigational and is not routinely used in clinical practice. Thus, as it stands, PD-L1 is an imperfect biomarker for predicting the response to ICI, but to date remains the only one tested prospectively.

Here, we look beyond PD-L1 expression as a selection tool for patients who are candidates for single-agent anti-PD-1/PD-L1 therapy, and provide practical guidance on how to identify patients most likely to benefit. We also provide guidance on the use of PD-1/PD-L1 inhibitors in specific clinical scenarios.

\section{Methods}

A comprehensive literature search of PubMed was performed to identify relevant studies that looked at associations between clinical characteristics and treatment outcome. Search terms included 'carcinoma, non-small-cell lung' (MESH major topic); immunotherapy, nivolumab, pembrolizumab, atezolizumab, durvalumab, avelumab, 
checkpoint inhibitor, PD-1, PD-L1; and predictive, prognostic, association, relationship, correlation, biomarker, subgroup. There were no restrictions on publication date or language. Additional papers were identified from reference lists and the authors' expert knowledge. The search was supplemented by searches of abstracts from the past year of key general oncology and lung cancer congresses, including the World Conference on Lung Cancer 2017, American Society of Clinical Oncology 2017, European Society for Medical Oncology 2017, and American Association for Cancer Research 2017.

\section{Clinical trials of ICI in NSCLC}

\section{PD-1 inhibitors}

Nivolumab (Opdivo ${ }^{\circledR}$; Bristol-Myers Squibb, NY, USA) is approved in Europe and the USA for pretreated locally advanced or metastatic NSCLC [34,35]. Approval of nivolumab was partly based on the results of two Phase III clinical trials that compared nivolumab with docetaxel as second-line treatment in patients with advanced squamous cell (CheckMate 017) or nonsquamous cell (CheckMate 057) NSCLC (Table 1). In both studies, median OS was longer in the nivolumab group compared with the docetaxel group, and the objective response rate was higher (CheckMate 017: 20 vs 9\%, p = 0.008; CheckMate 057: 19 vs 12\%, $\mathrm{p}=0.02$ ) [36,37]. Median PFS favored nivolumab in CheckMate 017 but not CheckMate 057; however, rates of PFS at 1 year were higher in the nivolumab group than the docetaxel group in both studies (CheckMate 017: 21 vs 6\%; CheckMate 057: 19 vs 8\%, respectively) [36,37].

Pembrolizumab (Keytruda ${ }^{\circledR}$; Merck, Kenilworth, NJ, USA) is also approved for relapsed locally advanced or metastatic NSCLC, although its use is restricted to patients with PD-L1 expression in $\geq 1 \%$ tumor cells $[47,48]$. In a Phase I trial of pembrolizumab (Keynote 001), improved clinical activity was observed in patients who expressed PD-L1 in at least 50\% of tumor cells [39]. Thus, in Keynote 010, a Phase II/III trial that followed, only patients with PD-L1-positive tumors (PD-L1 $\geq 1 \%$ ) were eligible for inclusion. Pembrolizumab ( $2 \mathrm{mg} / \mathrm{kg}$ ) prolonged OS compared with docetaxel in this patient population (HR: $0.71,95 \%$ CI: $0.58-0.88$ ), with the greatest impact on those expressing higher levels of PD-L1 [40]. The initial approval of pembrolizumab as second-line treatment in PD-L1-positive NSCLC was extended to first-line treatment in patients with high PD-L1-expressing tumors (PD-L1 > 50\%) with no EGFR or ALK mutations, following results of Keynote 024 [41]. In this study, treatment with pembrolizumab prolonged PFS and OS and improved objective response rates ( $45 \mathrm{vs} 28 \%$, respectively) compared with chemotherapy in the first-line setting [41]. Nivolumab was also trialed as first-line treatment in patients with PD-L1 expression in $\geq 1 \%$ of tumor cells in CheckMate 026, but it did not show an improvement in PFS or OS compared with platinum-based chemotherapy [28].

\section{PD-L1 inhibitors}

Atezolizumab (Tecentriq ${ }^{\circledR}$; F Hoffmann-La Roche/Genentech, Basel, Switzerland/CA, USA) is approved in Europe and the USA for second-line treatment of NSCLC following platinum-based chemotherapy [49,50]. Following positive results in two Phase II trials (POPLAR and BIRCH) [42,43], atezolizumab was compared with docetaxel in a Phase III study (OAK) in unselected patients who had received up to two previous chemotherapy regimens, including at least one platinum-based therapy. OS was significantly improved in the atezolizumab treatment group compared with the docetaxel group. This benefit was independent of the level of PD-L1 expression, with patients with low or undetectable PD-L1 expression also demonstrating a prolonged OS with atezolizumab versus docetaxel (12.6 vs 8.9 months; HR: 0.75, 95\% CI: 0.59-0.96) [44]. Other PD-L1 inhibitors in late-stage development for NSCLC include durvalumab (Imfinzi ${ }^{\circledR}$; AstraZeneca, Cambridge, UK) and avelumab (Bavencio ${ }^{\circledR}$; EMD Serona, MD, USA; Pfizer, NY, USA); data for both have recently been reported (Table 1) [45,46].

\section{Potential clinical characteristics for guiding patient selection for single-agent anti-PD-1/PD-L1 therapy}

In the following sections, we discuss the available evidence on the impact of age, smoking status, tumor histology, Eastern Cooperative Oncology Group (ECOG) performance status (PS), presence of brain metastases, speed of disease progression, response to previous treatment, treatment history and $E G F R / A L K$ mutational status on the response to ICI in NSCLC, and provide our recommendations on selecting patients for these treatments based on these factors. 
Table 1. Details of key clinical trials of checkpoint inhibitor monotherapy in non-small-cell lung cancer that included subgroup analyses.

\begin{tabular}{|c|c|c|c|c|c|c|c|}
\hline Trial & Phase & Setting & Study population & Immunotherapy arm & Active control arm & Primary end point & Ref. \\
\hline \multicolumn{8}{|l|}{ Nivolumab } \\
\hline CheckMate 012 & I & First line & - Stage IIIb/IV NSCLC & $\begin{array}{l}\text { Nivolumab } \\
3 \mathrm{mg} / \mathrm{kg} \mathrm{Q} 2 \mathrm{~W} \\
\mathrm{n}=52\end{array}$ & None & Safety & {$[55]$} \\
\hline CheckMate 017 & III & Second line & $\begin{array}{l}\text { - Stage IIIb/IV NSCLC } \\
\text { - Squamous cell histology }\end{array}$ & $\begin{array}{l}\text { Nivolumab } \\
3 \mathrm{mg} / \mathrm{kg} \text { Q2W } \\
\mathrm{n}=135\end{array}$ & $\begin{array}{l}\text { Docetaxel } \\
75 \mathrm{mg} / \mathrm{m}^{2} \mathrm{Q} 3 \mathrm{~W} \\
\mathrm{n}=137\end{array}$ & OS & [37] \\
\hline CheckMate 057 & III & $\begin{array}{l}\text { Second or } \\
\text { third line }\end{array}$ & $\begin{array}{l}\text { - Stage IIIb/IV NSCLC } \\
\text { - Nonsquamous cell } \\
\text { histology }\end{array}$ & $\begin{array}{l}\text { Nivolumab } \\
3 \mathrm{mg} / \mathrm{kg} \text { Q2W } \\
\mathrm{n}=287\end{array}$ & $\begin{array}{l}\text { Docetaxel } \\
75 \mathrm{mg} / \mathrm{m}^{2} \mathrm{Q} 3 \mathrm{~W} \\
\mathrm{n}=268\end{array}$ & OS & [36] \\
\hline CheckMate 026 & III & First line & $\begin{array}{l}\text { - Stage IV or recurrent } \\
\text { NSCLC } \\
\text { - PD-L1 tumor } \\
\text { expression } \geq 1 \%\end{array}$ & $\begin{array}{l}\text { Nivolumab } \\
3 \mathrm{mg} / \mathrm{kg} \text { Q2W } \\
\mathrm{n}=271\end{array}$ & $\begin{array}{l}\text { Platinum-based } \\
\text { chemotherapy Q3W } \\
n=270\end{array}$ & $\begin{array}{l}\text { PFS among patients with } \\
\text { PD-L1 expression } \geq 5 \%\end{array}$ & {$[28]$} \\
\hline \multicolumn{8}{|l|}{ Pembrolizumab } \\
\hline Keynote 001 & 1 & $\begin{array}{l}\text { First line or } \\
\text { later }\end{array}$ & $\begin{array}{l}\text { - Locally advanced or } \\
\text { metastatic NSCLC }\end{array}$ & $\begin{array}{l}\text { Pembrolizumab } \\
2 \mathrm{mg} / \mathrm{kg} \text { Q3W } \mathrm{n}=6 ; \\
10 \mathrm{mg} / \mathrm{kg} \text { Q3W } \mathrm{n}=287 \\
10 \mathrm{mg} / \mathrm{kg} \text { Q2W } \mathrm{n}=202\end{array}$ & None & $\begin{array}{l}\text { Safety and antitumor } \\
\text { activity plus efficacy in } \\
\text { previously-treated } \\
\text { patients with high } \\
\text { expression of PD-L1 }\end{array}$ & [39] \\
\hline Keynote 010 & II/III & $\begin{array}{l}\text { Second line } \\
\text { or later }\end{array}$ & $\begin{array}{l}\text { - Stage IIIb/IV or recurrent } \\
\text { NSCLC } \\
\text { - PD-L1 tumor proportion } \\
\text { score } \geq 1 \%\end{array}$ & $\begin{array}{l}\text { Pembrolizumab } \\
2 \mathrm{mg} / \mathrm{kg} \text { Q3W } \mathrm{n}=345 \\
10 \mathrm{mg} / \mathrm{kg} \text { Q3W } \mathrm{n}=346\end{array}$ & $\begin{array}{l}\text { Docetaxel } \\
75 \mathrm{mg} / \mathrm{m}^{2} \mathrm{Q} 3 \mathrm{~W} \\
\mathrm{n}=343\end{array}$ & $\begin{array}{l}\text { OS and PFS in total } \\
\text { population and in patients } \\
\text { with PD-L1 tumor } \\
\text { proportion score } \geq 50 \%\end{array}$ & [41] \\
\hline Keynote 024 & III & First line & $\begin{array}{l}\text { - Stage IV NSCLC } \\
\text { - No sensitising EGFR } \\
\text { mutations or } A L K \\
\text { translocations } \\
\text { - PD-L1 tumor proportion } \\
\text { score } \geq 50 \%\end{array}$ & $\begin{array}{l}\text { Pembrolizumab } \\
200 \text { mg fixed dose Q3W } \\
n=154\end{array}$ & $\begin{array}{l}\text { Platinum-based } \\
\text { chemotherapy } \\
n=151\end{array}$ & PFS & {$[42]$} \\
\hline \multicolumn{8}{|l|}{ Atezolizumab } \\
\hline $\mathrm{BIRCH}$ & II & $\begin{array}{l}\text { First to third } \\
\text { line or later }\end{array}$ & $\begin{array}{l}\text { - Stage IIIb/IV or recurrent } \\
\text { NSCLC } \\
\text { - PD-L1 expression level of } \\
\text { TC2 } / 3 \text { and } / \text { or IC2 } / 3^{\dagger} \\
\text { - No brain metastases }\end{array}$ & $\begin{array}{l}\text { Atezolizumab } \\
1200 \mathrm{mg} \text { fixed dose Q3W } \\
\mathrm{n}=659\end{array}$ & None & Objective response rate & {$[42]$} \\
\hline POPLAR & II & $\begin{array}{l}\text { Second or } \\
\text { third line }\end{array}$ & - Advanced NSCLC & $\begin{array}{l}\text { Atezolizumab } \\
1200 \mathrm{mg} \text { fixed dose Q3W } \\
\mathrm{n}=144\end{array}$ & $\begin{array}{l}\text { Docetaxel } \\
75 \mathrm{mg} / \mathrm{m}^{2} \mathrm{Q} 3 \mathrm{~W} \\
\mathrm{n}=143\end{array}$ & $\begin{array}{l}\text { OS in ITT population and } \\
\text { PD-L1 subgroups }\end{array}$ & {$[45]$} \\
\hline OAK & III & $\begin{array}{l}\text { Second or } \\
\text { third line }\end{array}$ & $\begin{array}{l}\text { - Stage IIIb/IV or recurrent } \\
\text { NSCLC }\end{array}$ & $\begin{array}{l}\text { Atezolizumab } \\
1200 \mathrm{mg} \text { fixed dose Q3W } \\
\mathrm{n}=425\end{array}$ & $\begin{array}{l}\text { Docetaxel } \\
75 \mathrm{mg} / \mathrm{m}^{2} \mathrm{Q} 3 \mathrm{~W} \\
\mathrm{n}=425\end{array}$ & $\begin{array}{l}\text { OS in ITT population and } \\
\text { PD-L1 subgroups }\end{array}$ & [47] \\
\hline \multicolumn{8}{|l|}{ Avelumab } \\
\hline $\begin{array}{l}\text { JAVELIN Solid } \\
\text { Tumor }\end{array}$ & $\mathrm{lb}$ & $\begin{array}{l}\text { Second line } \\
\text { or later }\end{array}$ & $\begin{array}{l}\text { - Stage IIIb/IV NSCLC } \\
\text { - No brain metastases }\end{array}$ & $\begin{array}{l}\text { Avelumab } \\
10 \mathrm{mg} / \mathrm{kg} \text { Q2W } \\
\mathrm{n}=184\end{array}$ & None & Safety & {$[45]$} \\
\hline \multicolumn{8}{|l|}{ Durvalumab } \\
\hline PACIFIC & III & $\begin{array}{l}\text { Second line } \\
\text { or later }\end{array}$ & $\begin{array}{l}\text { - Stage III locally advanced } \\
\text { NSCLC } \\
\text { - Previously received } \\
\text { chemoradiation }\end{array}$ & $\begin{array}{l}\text { Durvalumab } \\
10 \mathrm{mg} / \mathrm{kg} \text { Q2W } \\
\mathrm{n}=476\end{array}$ & Placebo $n=237$ & PFS and OS & [46] \\
\hline $\begin{array}{l}\text { †PD-L1 TC expres } \\
\text { positive (IC3 } \geq 10^{\circ} \\
\text { IC: Tumor-infiltrati } \\
\text { Every } 3 \text { weeks. }\end{array}$ & $\begin{array}{l}\text { was sC } \\
\text { immune }\end{array}$ & $\begin{array}{l}\text { as a percentag } \\
\text { ut }<10 \%) \text {. } \\
\text { ITT: intent-to-t }\end{array}$ & $\begin{array}{l}\text { of PD-L1-positive TC (TC3 } \geq 50 \\
\text { at; NSCLC: Non-small-cell lung }\end{array}$ & $\begin{array}{l}\% \text { or TC2 } \geq 5 \% \text { but }<50 \% \text { ). } \\
\text { cancer; OS: Overall survival; P }\end{array}$ & $\begin{array}{l}\text { D-L1 IC expression was } \\
\text { : Progression-free surviv }\end{array}$ & $\begin{array}{l}\text { as a percentage of tumor area } \\
\text { Iumor cell; Q2W: Every } 2 \text { weeks }\end{array}$ & stained \\
\hline
\end{tabular}

Age

Age-associated deterioration of the immune system may impact the effectiveness of immunotherapies, which rely on the competent functioning of various immunological components [51]. This has implications for the treatment of lung cancer, which mostly occurs in older people, with an average age at diagnosis of 70 years [52]. Although many 


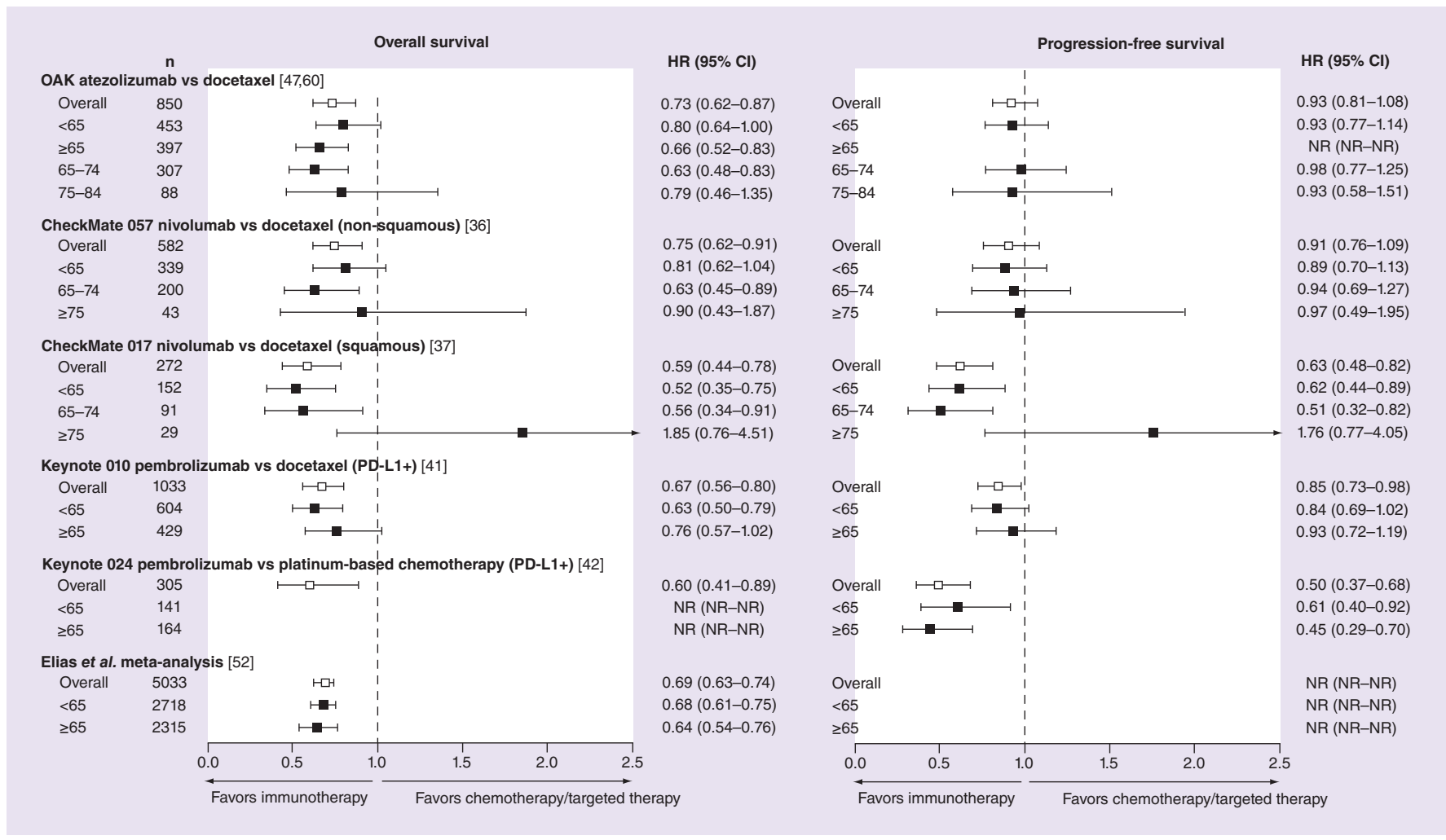

Figure 1. Efficacy of immunotherapy in non-small-cell lung cancer according to age. Data shown are published $\mathrm{HR}$ and $95 \% \mathrm{Cl}$ values from each trial (or from published meta-analyses); no reanalyses have been performed for the purposes of the current article. HR: Hazard ratio; NR: Not reported.

of the Phase III trials of PD-1/PD-L1 inhibitors in NSCLC have assessed the effectiveness of the ICI according to age, no clear age-associated differences have emerged. Generally, improved survival was evident in patients treated with anti-PD-1/PD-L1 therapies versus chemotherapy, regardless of the age group assessed (Figure 1) [36,40,41,44]. In CheckMate 017, data suggest that nivolumab is less effective than docetaxel in patients aged 75 years or older. However, the small number of patients included within this subgroup (11 and 18 patients in the nivolumab and docetaxel groups, respectively) precludes any firm conclusions being drawn [37]. A meta-analysis of nine randomized controlled trials involving over 5000 patients with NSCLC treated with nivolumab, pembrolizumab or atezolizumab versus chemotherapy/targeted therapy concluded that the efficacy of PD-1/PD-L1 inhibitors was similar in patients over 65 years of age compared with those who were younger [53]. In the Phase II trial CheckMate 171 evaluating nivolumab monotherapy, the estimated 6-month OS rate was $66 \%$ in the subgroup of patients aged $\geq 70$ years $(n=279)$ versus $67 \%$ in the overall population $(n=809)$. Tolerability was also comparable with 56 and $50 \%$, respectively, experiencing treatment-related adverse events (AEs) [54]. Similar findings were observed in CheckMate 153, a community-based Phase III/IV safety trial of nivolumab in which $40 \%$ of the study population were aged $\geq 70$ years. Estimated OS at 6 -months was $63 \%$ in both this subgroup of patients and the overall study population with similar proportions experiencing treatment-related AEs (62 vs 60\%, respectively) [55].

Thus, there is sufficient evidence against using age as a factor for selecting patients for anti-PD-1/PD-L1 therapy and it should not be used to deny a patient treatment, particularly as these drugs offer a less toxic alternative to chemotherapy.

\section{Smoking status}

Exposure to tobacco smoke has long been recognized as the single most important contributing cause of lung cancer. Most patients included in clinical trials of PD-1/PD-L1 inhibitors in NSCLC have been former or current smokers. Some trials have analyzed responses according to smoking status and results suggest a reduced benefit of anti-PD-1/PD-L1 antibodies in never smokers (Figure 2) [36,41,43,44]. In Keynote 001, the overall response rate 


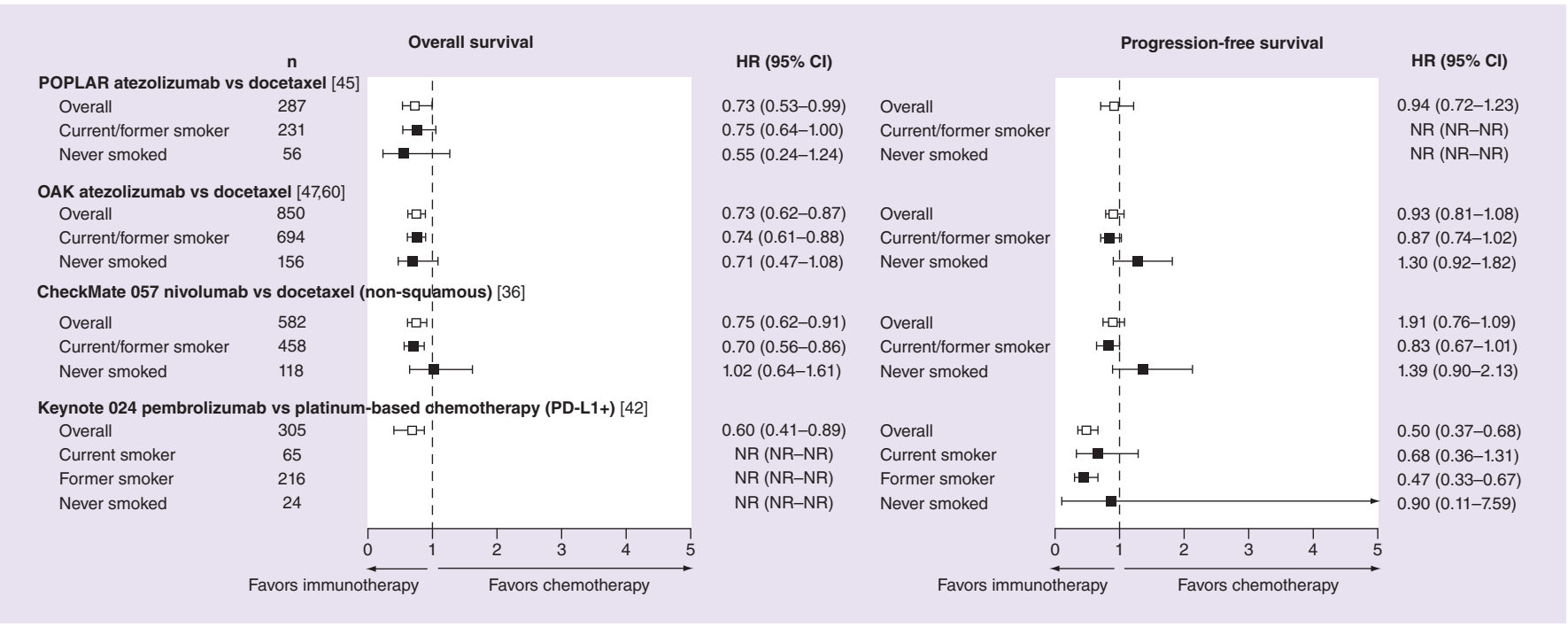

Figure 2. Efficacy of immunotherapy in non-small-cell lung cancer according to smoking status. Data shown are published HR and $95 \%$ $\mathrm{Cl}$ values from each trial; no reanalyses have been performed for the purposes of the current article.

HR: Hazard ratio; NR: Not reported.

(ORR) to pembrolizumab was lower in the never smoker group compared with former/current smokers (10 vs 22\%, respectively) [39]. This observation was repeated in the Phase I CheckMate 012 trial in patients treated with first-line nivolumab monotherapy where ORR was 9 and 33\% for never smokers and former/current smokers, respectively [38]. A subgroup analysis of CheckMate 057 suggested an OS benefit with nivolumab over docetaxel in patients with a history of smoking that was not evident in the never smokers' group [36]. Conversely, in OAK and POPLAR, the OS benefit of atezolizumab over docetaxel was observed regardless of smoking status (Figure 2) [43,44]. A systematic review showed that current/former smokers seem to derive greater survival benefit from PD-1/PD-L1 inhibitors over docetaxel (HR: 0.71, 95\% CI: 0.63-0.82; $\mathrm{p}<0.00001$ ) compared with never smokers (HR: 0.79, 95\% CI: 0.60-1.06; $\mathrm{p}=0.11$ ) [56].

Available evidence suggests that the higher ORR observed in patients who are current or former smokers is likely due to the higher TMB associated with this population [57]. Thus, TMB, rather than smoking status, is likely more relevant when determining the most appropriate treatment, but this at present remains investigational. Smoking status should not therefore be used to select patients for anti-PD-1/PD-L1 therapy.

\section{Tumor histology}

The use of a number of drugs for NSCLC - including bevacizumab, nintedanib and pemetrexed - is restricted to certain tumor histologies [58,59]. The efficacy of ICI in NSCLC; however, appears to be largely independent of histology subtype, with improved OS and/or PFS in patients with both squamous and nonsquamous histologies treated with anti-PD-1/PD-L1 therapies versus chemotherapy evident (Figure 3) $[36,37,40,41,43,60]$. Data on rarer histological types, such as large cell lung cancer, are lacking. Although most Phase III trials have not selected for histology, CheckMate 017 and CheckMate 057 recruited only patients with squamous or nonsquamous cell carcinoma, respectively [36,37]. Both trials demonstrated a significant improvement in OS favoring nivolumab over docetaxel [36,37], with a clinical benefit still evident at 3 years regardless of histology [61]. However, in the squamous cell population, the benefit of nivolumab was comparable across PD-L1 expression levels, while in the nonsquamous cell population ( $93 \%$ of whom had adenocarcinomas), the magnitude of benefit was greater in those who expressed PD-L1 $(\geq 1 \%)$ compared with those who did not [36,37]. Similarly, in OAK, OS was prolonged with atezolizumab versus docetaxel regardless of histology type [44], yet efficacy was correlated with PD-L1 expression in the nonsquamous cell population only (Figure 3) [60]. In post hoc multivariate analysis of Keynote 010 , nonsquamous histology was independently associated with better OS versus squamous histology among patients treated with pembrolizumab (HR: 0.55, 95\% CI: 0.43-0.70; p < 0.0001) [62]. Conversely, in a retrospective Japanese study, multivariate logistic regression identified squamous histology to be independently associated with a higher objective response rate with nivolumab (67 vs 11\%; $\mathrm{p}=0.004)$ [63]. As squamous histology 


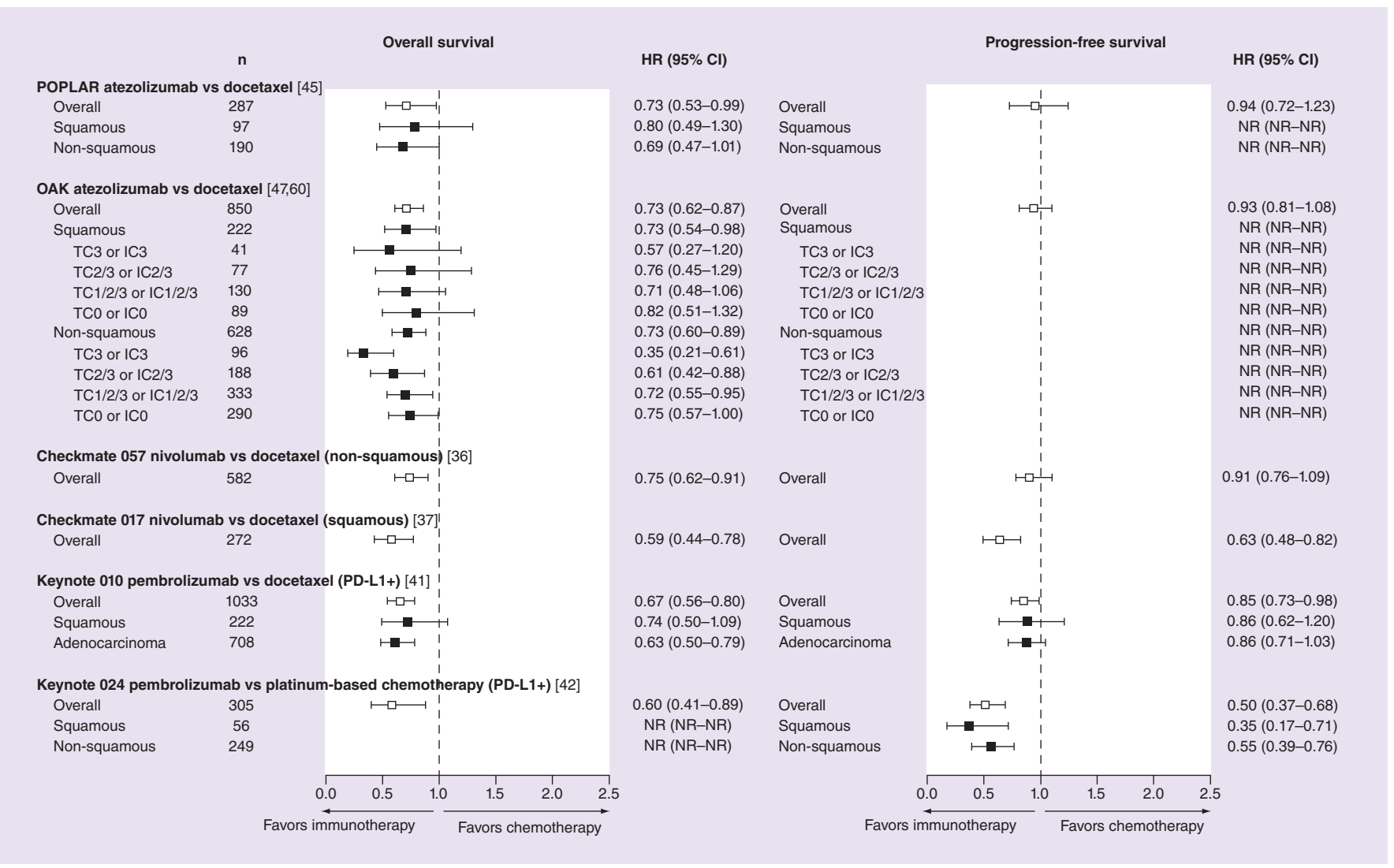

Figure 3. Efficacy of immunotherapy in non-small-cell lung cancer according to histology type. Data shown are published HR and $95 \%$ $\mathrm{Cl}$ values from each trial; no reanalyses have been performed for the purposes of the current article.

HR: Hazard ratio; IC: Tumor-infiltrating immune cell; NR: Not reported; TC: Tumor cell.

has been found to be independently associated with high expression of PD-L1 [64], it is likely that PD-L1 expression rather than tumor histology may underlie any difference seen between squamous and nonsquamous populations, and therefore may be biasing post hoc analyses.

Due to the influence of PD-L1 expression, not to mention the association between smoking status and histology type, and the insufficient evidence for a survival benefit in one population over another, we do not recommend using histology as a factor to select patients more likely to benefit from anti-PD-1/PD-L1 therapies.

\section{ECOG performance status}

Most randomized controlled trials of anti-PD-1/PD-L1 drugs in NSCLC performed to date have excluded patients with an ECOG PS $\geq 2$. Therefore, clinical evidence in this subgroup of patients is limited. Recent results from two trials of nivolumab that have included patients with PS2 have both demonstrated lower estimated 6-month OS rates in PS2 patients compared with the overall study population (CheckMate 171: 46 vs 67\%; CheckMate 153: 41 vs 63\%) [54,55]. No clear differences in survival have emerged from the clinical data between PS0 and PS1 patients (Figure 4) $[36,37,40,41,44]$. Ongoing studies are evaluating the use of anti-PD-1/PD-L1 therapies in the PS2 setting $[65,66]$, and until further clinical evidence has been generated from such studies, we do not recommend using these therapies in patients with PS $\geq 2$.

\section{Presence of brain metastases}

NSCLC patients with brain metastases represent a group with poor prognosis [67]. Most trials of ICIs in pretreated $[36,37,39,40,43,44]$ and treatment-naive NSCLC patients [28,38,41] have allowed individuals with treated and/or stable brain metastases. Clinical evidence to date on the use of anti-PD-1/PD-L1 drugs in this population has shown varied results. In CheckMate 057, there was no OS benefit of nivolumab over docetaxel for patients with brain metastases (HR: 1.04, 95\% CI: 0.62-1.76) [36]. However, in OAK, an OS benefit of atezolizumab over docetaxel 


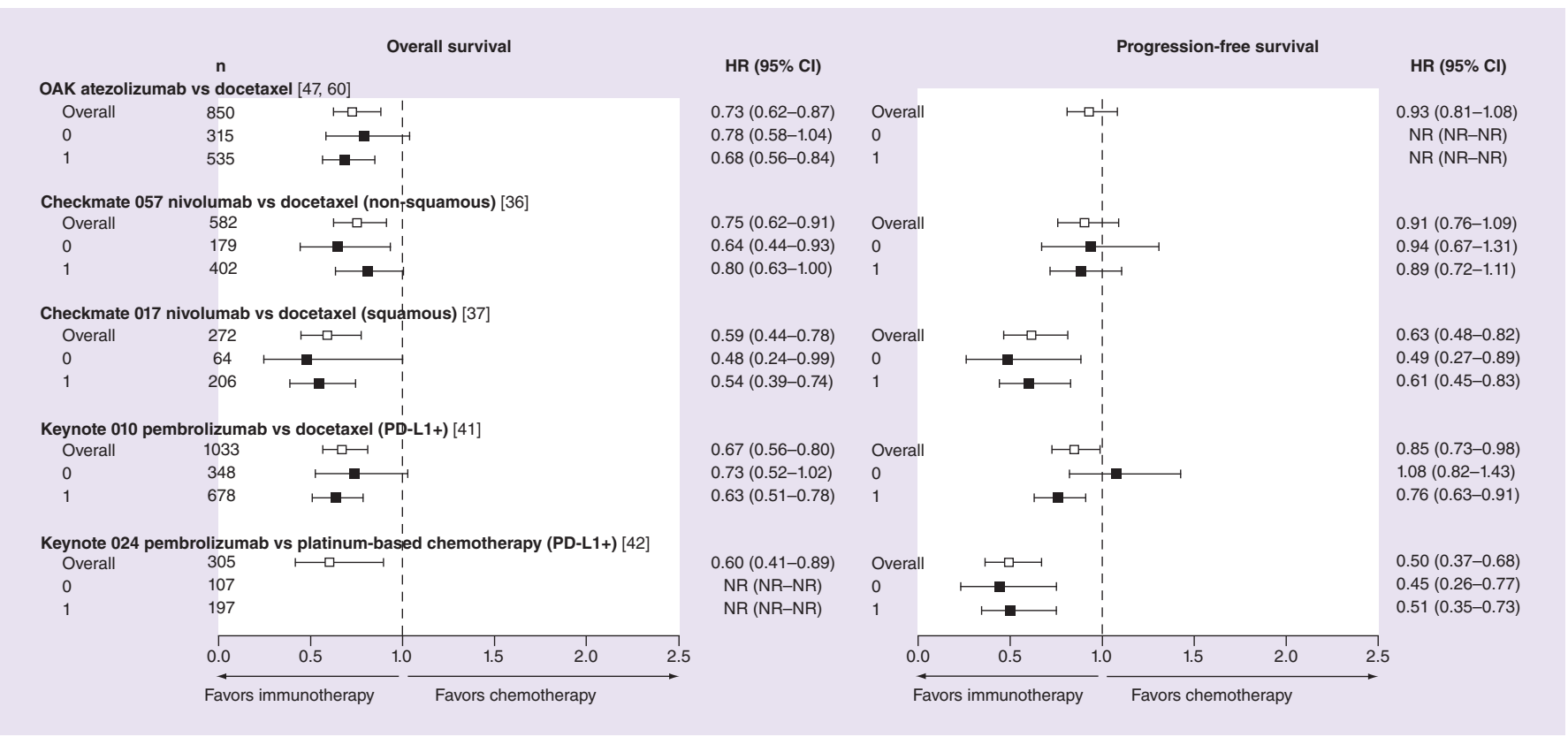

Figure 4. Efficacy of immunotherapy in non-small-cell lung cancer according to Eastern Cooperative Oncology Group performance status. Data shown are published HR and $95 \% \mathrm{Cl}$ values from each trial; no reanalyses have been performed for the purposes of the current article.

HR: Hazard ratio; NR: Not reported.

was evident in patients with treated brain metastases at baseline (HR: 0.54, 95\% CI: 0.31-0.94), with a similar outcome for PFS (HR: 0.61, 95\% CI: 0.38-0.99) [44]. Treatment of patients with active, symptomatic or untreated brain metastases with PD-1/PD-L1 inhibitors cannot be recommended due to a lack of clinical evidence in this population and the concern that an increase in lesion size due to inflammatory response may lead to worsening neurological symptoms. However, patients who have received treatment for brain metastases, are asymptomatic, and are clinically and radiologically stable without the need for corticosteroids (or are on a stable or decreasing dose of $\leq 10 \mathrm{mg}$ daily prednisone [or equivalent]) could be considered suitable candidates for anti-PD-1/PD-L1 therapy.

\section{Speed of disease progression/response to prior treatment}

Hyperprogression has been reported in some cancer patients receiving immunotherapy treatment, including NSCLC [68]. In one study, 40 (16\%) of 242 patients with advanced NSCLC were reported to have hyperprogressive disease (HPD). Despite similar clinical, molecular and pathological characteristics, including PD-L1 status, patients with HPD had significantly poorer survival outcomes compared with those without HPD [69]. In this study, the response to treatment prior to receiving immunotherapy was also similar between patients who developed HPD and those who did not. There is evidence however, that suggests that patients who achieve progressive disease as the best response to the previous line of treatment may not derive as much OS benefit from single-agent PD-1 pathway inhibitors as those who achieve disease control [63]. In a retrospective study of 50 patients with advanced NSCLC, those who responded to the treatment received prior to nivolumab monotherapy had a significantly higher ORR to nivolumab than non-responders (47 vs 3\%; $\mathrm{p}<0.0001$ ) [63]. Similarly, in another study, patients who derived a clinical benefit from first-line chemotherapy had improved PFS and OS with nivolumab compared with those whose best response to chemotherapy was progressive disease [70]. Whether this is due to the chemotherapy responder population being enriched with patients with immunologically 'hot' tumors is unknown. A post hoc multivariate analysis of CheckMate 057 demonstrated that patients with poor prognostic factors, including progressive disease as the best response to prior treatment and a shorter time since the last treatment, and/or more aggressive disease together with low or no PD-L1 expression, had a higher risk of death on nivolumab in the first 3 months of treatment versus docetaxel [71]. It will be important to evaluate whether the length of disease-free survival after previous treatment is a reflection of pre-existing immune responses as has been reported in cervical cancer [72]. As 
the median time to respond to single-agent anti-PD-1/PD-L1 therapy is approximately $2-3$ months [28,36,37,39-41], this delayed onset of effect should be considered before initiating treatment in patients who have progressed during or within 3 months of completion of the previous line of therapy. Docetaxel monotherapy may be more appropriate for these patients. In cases of adenocarcinoma, adding nintedanib may be suitable as this combination has shown improved OS benefits in patients with early progression or progressive disease as a best response after first-line treatment [73].

\section{Treatment history}

A post hoc analysis of the Keynote 001 trial examined the impact of previously received radiotherapy on the clinical activity of pembrolizumab. The patients who had received radiotherapy prior to pembrolizumab demonstrated longer PFS (HR: 0.56, 95\% CI: 0.34-0.91; $\mathrm{p}=0.019$ ) and OS (HR: 0.58, 95\% CI: 0.36-0.94; $\mathrm{p}=0.026$ ) compared with patients who had not received radiotherapy [74]. A meta-analysis of 19 clinical trials of anti-PD-1/PD-L1 drugs revealed that treatment-naive patients had a significantly better response to these treatments compared with those who had previously received chemotherapy [75]. In CheckMate 057, an OS benefit for nivolumab over docetaxel was not observed in the subset of patients who had received nivolumab in the third-line setting (HR: 1.34, 95\% CI: $0.73-2.43$ ) [36]. These results suggest that there is a potential association between previously received treatment and the response to anti-PD-1/PD-L1 therapies, but these relationships have yet to be validated and should be considered exploratory.

\section{Mutational status}

EGFR \& ALK

Genetic alterations in EGFR and $A L K$ have been identified as key driver mutations contributing to the development of NSCLC, and occur in approximately $10-35 \%$ and $3-7 \%$ of patients, respectively [76]. Tumors harboring these mutations are more common in NSCLC patients with adenocarcinomas and in 'never' or light smokers [76], who usually have a low TMB [77]. Trials of pembrolizumab and nivolumab in first-line setting (Keynote 024 and CheckMate 026) have excluded patients with EGFR or ALK mutations. However, Phase III trials of atezolizumab, nivolumab and pembrolizumab in the second-line setting or later have all demonstrated a lack of survival benefit with these treatments over chemotherapy in patients with EGFR mutant NSCLC (Figure 5) [36,40,44,60]. This has been confirmed in a recent meta-analysis [78] and corroborated in other studies [79]. In the BIRCH trial, ORRs were lower in previously-treated $E G F R$ mutant-positive patients treated with atezolizumab compared with EGFRwild-type patients [42]. In the JAVELIN solid tumor trial, no confirmed responses to avelumab were reported in patients ( $\mathrm{n}=10)$ with $E G F R$ mutations or $A L K$ translocations [45]. Licences for pembrolizumab and atezolizumab specifically state that patients with $E G F R$ or $A L K$ genomic aberrations should have disease progression on a targeted therapy as well chemotherapy before receiving these drugs [47-50]. Thus, we would suggest that these patients should be considered for treatment with anti-PD-1/PD-L1 therapies only after all the other standard treatment options (i.e., tyrosine-kinase inhibitors and chemotherapy) have been exhausted.

\section{KRAS}

KRAS mutations are detected in around $30 \%$ of NSCLCs and are more common in patients with adenocarcinomas and smokers [80]. At present, there is no approved targeted treatment for KRAS mutant NSCLC. ICIs have been proposed as a potential treatment option in these patients, partly due to the higher incidence of $K R A S$ mutations among smokers [80]. The efficacy of anti-PD-1/PD-L1 therapy according to KRAS mutation status has been investigated in subgroup analyses of some clinical trials with varied results (Figure 5). In OAK, the OS benefit of atezolizumab over docetaxel was similar between KRAS mutant and wild-type patients [44]. In CheckMate 057, $\mathrm{PFS}$ was longer in the chemotherapy arm versus nivolumab for patients with wild-type $K R A S$ [36]. A meta-analysis of OAK, CheckMate 057 and POPLAR found that ICIs prolonged OS over docetaxel in patients with a KRAS mutation (HR: $0.64,95 \%$ CI: 0.43-0.96; $\mathrm{p}=0.03$ ), but not in those with wild-type tumors [81]. As evidence suggests that NSCLC patients with or without KRAS mutations can benefit from PD-1 pathway inhibitors, KRAS mutational status should not be used to select patients for treatment with anti-PD-1/PD-L1 therapy.

\section{Other mutational markers}

$M E T$ exon 14 skipping mutations, high-level MET amplification and BRAF and ROS1 mutations have all been identified as important driver events in NSCLC, occurring in 1-3\% of lung cancers [76,82]. A study investigating the 


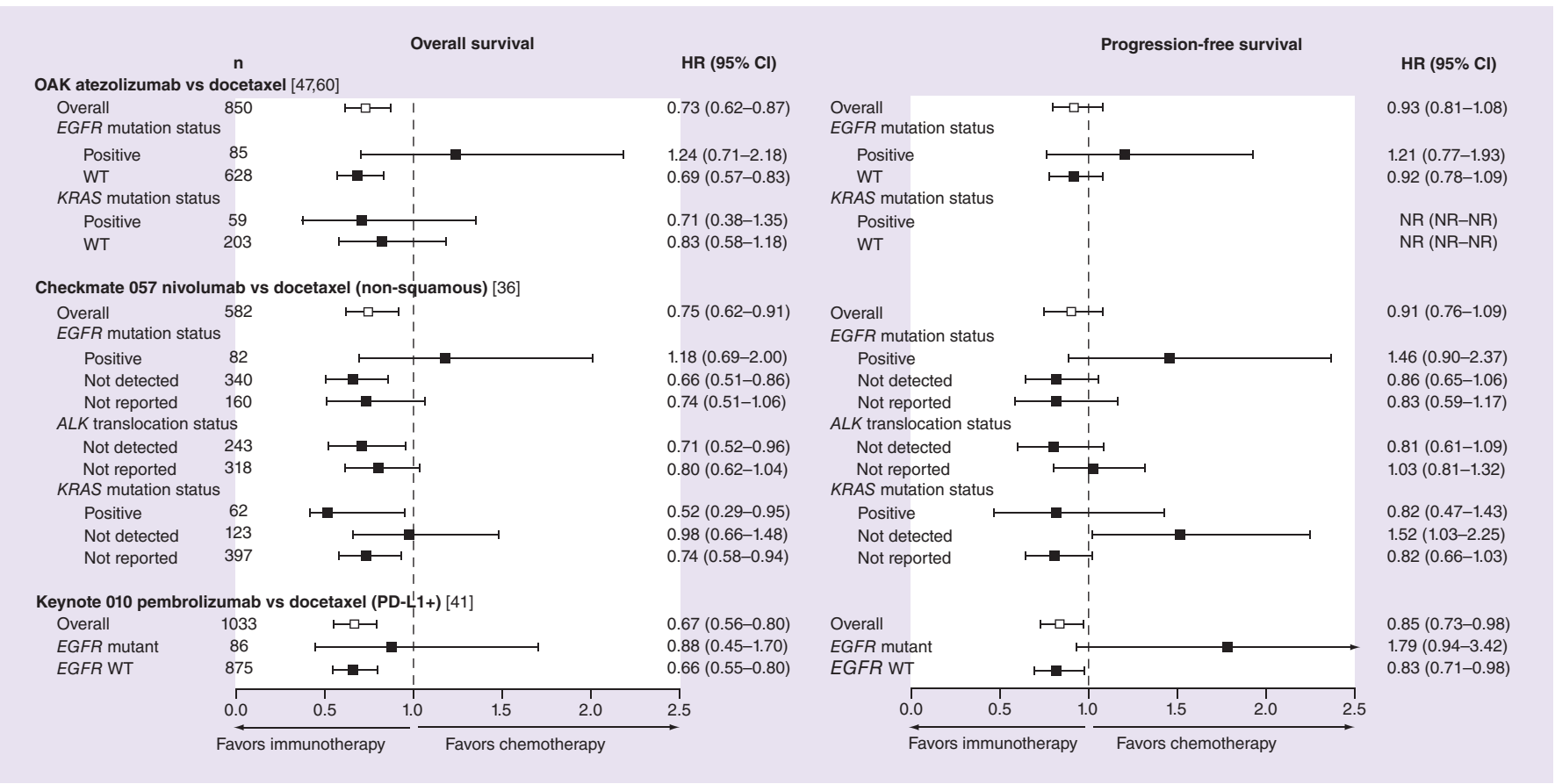

Figure 5. Efficacy of immunotherapy in non-small-cell lung cancer according to mutational status. Data shown are published HR and $95 \% \mathrm{Cl}$ values from each trial; no reanalyses have been performed for the purposes of the current article.

HR: Hazard ratio; NR: Not reported; WT: Wild-type.

effectiveness of ICIs in MET exon 14-mutated NSCLC patients concluded that, despite frequent PD-L1 expression, treatment responses were uncommon and lower than those observed with $M E T$-targeted therapy [83]. This may be explained by the lower TMB in tumors that harbor MET exon 14 alterations; a characteristic shared in $B R A F$ and ROS1 mutant NSCLC [84-86] Evidence on the impact of these mutations on the response to anti-PD-1/PD-L1 antibodies is scant. Thus, we do not recommend selecting patients on this basis.

\section{The use of single-agent anti-PD-1/PD-L1 therapies in clinically challenging populations \\ Patients with pre-existing autoimmune disease or conditions requiring systemic immunosuppression}

Approximately 14-25\% of patients with NSCLC have a co-existing autoimmune disease [87]. The presence or history of active autoimmune disease is an established contraindication to immunotherapy due to the potential for disease flare-up and worse immune-related toxicity. For the same reason, patients with an active, known or suspected history of autoimmune disease have predominantly been excluded from clinical trials of anti-PD-1/PDL1 inhibitors in NSCLC. In a recent retrospective analysis of 46 NSCLC patients with autoimmune disease treated with PD-1 pathway inhibitors, symptomatic flare of the underlying autoimmune disease was uncommon, occurring in only eight (17\%) patients [88], leading to the temporary interruption of anti-PD-1 treatment in three (7\%) patients. The proportion of patients reporting at least one immune-related AE (irAE; 26\%) was similar to previous reports in patients without autoimmune diseases. All events were considered unrelated to the underlying autoimmune condition [88]. A meta-analysis of 49 case reports, case series and observational studies that included 123 patients with cancer and a pre-existing autoimmune disease treated with ICI found that $92(75 \%)$ patients experienced an exacerbation of the autoimmune disease, an irAE or both, but concluded that these could usually be managed without discontinuation of ICI therapy [89].

The use of PD-1/PD-L1 inhibitors in patients with active autoimmune disease requiring systemic treatment is not recommended. However, in patients who have not experienced a flare-up of disease for 2 years and do not require immunosuppressive treatment (except for prednisone $\leq 10 \mathrm{mg}$ daily or equivalent), these treatments could still be considered. This approach would necessitate a full and open discussion with the patient to ensure that they are aware of the possible risk of a flare-up, and close monitoring of the patient throughout treatment. The 
potential risk-benefit should be considered on an individual basis, taking into account the organ(s) targeted and the etiopathogenetic mechanism of the autoimmune disease. It should be noted that most clinical trials allowed systemic treatment with low-dose corticosteroids ( $\leq 10 \mathrm{mg}$ of prednisolone or equivalent). Patients requiring regular high-dose corticosteroid or immunosuppression respond less frequently to immunotherapy [90]. If possible, treating physicians should try and reduce the steroid dose to prednisone $\leq 10 \mathrm{mg}$ daily (or equivalent) before commencement of anti-PD-1/PD-L1 therapy, to see if the patient is able to tolerate it.

\section{Renal or hepatic dysfunction}

Clinical trials of PD-1 pathway inhibitors in NSCLC have largely excluded patients with renal or hepatic impairment. However, evidence suggests that ICIs can be a well-tolerated therapeutic option in these patients [91,92]. In a study of 27 patients with advanced solid tumors and impaired cardiac, renal or hepatic function, treatment with anti-PD-1 agents was associated with tolerable irAEs and infrequent and manageable worsening of organ function [92]. A case series of melanoma patients with chronic kidney failure and an organ transplant recipient treated with ICIs also suggests anti-PD-1 antibodies can be used safely in patients with impaired kidney function [91]. As monoclonal antibodies are metabolized into peptides and amino acids by intracellular catabolism, and not by the liver or kidney, hepatic or renal dysfunction are likely to have little effect on the pharmacokinetics of these drugs [93]. Due to the challenges associated with treating patients with impaired kidney or liver function with systemic cytotoxic drugs, anti-PD-1/PD-L1 agents provide an alternative and safe treatment option for some of these patients. In our opinion, those with mild to moderate kidney dysfunction (i.e., glomerular filtration rate $>30 \mathrm{ml} / \mathrm{min}$ ), or grade 1 hepatic impairment (i.e., alanine aminotransferase $<3 \times$ upper limit of normal or total bilirubin $<1.5 \times$ upper limit of normal) can be considered candidates for treatment with ICIs. However, caution should be taken for patients with severe kidney disease (i.e., glomerular filtration rate $\leq 30 \mathrm{ml} / \mathrm{min}$ ). Specifically, patients with immune-related renal dysfunction, such as glomerulonephritis, should not be treated unless there is a clear understanding that renal failure might require management by dialysis and that this is an acceptable consequence to the patient. Treatment of NSCLC patients with grade 2 or 3 liver-specific AEs with anti-PD-1/PD-L1 therapies is not recommended.

\section{Future perspective}

Detailed discussion of the complex interactions between PD-L1-expressing tumor cells and host-immune cells within the tumor microenvironment is beyond the scope of the current article. However, it is important to note that such relationships are likely to underlie the influence on outcomes of some of the clinical factors discussed above, and may also explain the potential role of emerging biomarkers, such as TMB [94]. The utility of TMB as a predictor of response to immunotherapy has generated much attention, not just in NSCLC [95], but it has not yet been tested prospectively in lung cancer. Other potential biomarkers of response have also been proposed, including immune-related gene signatures [43,96], and baseline hematological measures, such as neutrophil-lymphocyte ratio [97]. Notably, TMB and neoantigen formation are increased in tumors with DNA repair deficiencies caused by, for example, loss-of-function mutations in homologous recombination and mismatch repair (MMR) genes [98]. In tumors with deficient mismatch repair (dMMR) and microsatellite instability (MSI), a high mutational and neoantigen burden is associated with a favorable response to ICI [99]. Le et al. reported objective radiographic responses in 53\% (46/86) of patients with dMMR tumors treated with pembrolizumab in a range of different cancer types and a 2-year OS rate of 64\%; however, no patient with NSCLC was included in this study [99]. Based on similar data from 159 patients across five multicohort, single-arm clinical trials, the FDA granted the first tissue/site-agnostic approval to pembrolizumab in 2017 for patients with progressive dMMR or MSI-high advanced solid tumors [100]. Beyond MMR and MSI, one of the emerging mutations with a predictive role is polymerase $\epsilon$ (POLE), which can compromise DNA repair and replication mechanisms in a similar way to dMMR. In a recent analysis from 15,529 lung cancer tumors, only $0.3 \%$ were MSI-high and $1.0 \%$ had mutations in DNA repair genes (MLH1, MSH2, POLE); the presence of either correlated with a high TMB ( $\mathrm{p}<0.0001)$ [85]. A link between DNA repair deficiencies, TMB, neoantigen load and tumor-infiltrating lymphocytes has been demonstrated in lung adenocarcinoma [101], but further study is required to correlate this with ICI efficacy.

The validation of predictive markers for immunotherapy and the incorporation of routine testing into clinical practice would be an important step in identifying patients most likely to benefit from these drugs. It may be necessary to combine multiple biomarkers that capture different aspects of the tumor-immune cell interaction in order to accurately predict the response to ICIs. Cancer immunograms are one method for integrating biomarkers 
and have been applied to lung cancer patients to identify different phenotypes [102]. Immunograms build a picture of the patient-specific tumor microenvironment and have the potential to be utilized for optimal personalized immunotherapy $[102,103]$.

This paper has focused on the use of PD-1/PD-L1 inhibitors as monotherapy as this is most relevant to clinical practice at this time. However, this is a rapidly evolving field and the use of these drugs in combination with other ICI or with other treatment strategies, and in earlier stages of lung cancer, is currently under investigation and will likely be part of the oncology treatment landscape in the future.

\section{Conclusion}

We acknowledge that much of the evidence presented here is from post hoc subgroup analyses of randomized controlled trials, which has inherent limitations, but we believe that patients should not be selected for PD-1/PDL1 inhibitor treatment based on their age, smoking status, tumor histology or treatment history. This conclusion is supported by results of a recent meta-analysis of many of these trials [104]. Current data do not support use of these drugs in patients with PS $\geq 2$ who should be offered entry into a clinical trial if possible. The patients with untreated brain metastases, grade $2 / 3$ liver-specific AEs, or active autoimmune disease requiring chronic systemic treatment should not receive PD-1/PD-L1 inhibitors. For the patients who have treated/stable brain metastases or autoimmune diseases that require only low-dose steroids (prednisone $\leq 10 \mathrm{mg}$ daily or equivalent), PD-1/PD-L1 inhibitors should be still considered as a therapeutic option. The patients with autoimmune diseases for whom a flare-up would cause serious morbidity should be treated with great caution, as should those who have progressed on or within 3 months of completing the previous line of treatment and those with severe kidney disease. Those with targetable driver mutations should only receive anti-PD-1/PD-L1 drugs once all other standard treatment options have failed.

\section{Executive summary}

\section{Background}

- Inhibitors of the PD-1/PD-L1 pathway offer improved outcomes in some patients with advanced non-small-cell lung cancer (NSCLC), but not all.

- Identifying patients with NSCLC who will benefit from anti-PD-1/PD-L1 inhibitors remains an unmet need.

- Expression of PD-L1 has demonstrated some utility as a predictor of response to PD-1/PD-L1 inhibitors but has its limitations.

- Emerging biomarkers such as tumor mutational burden show promise but have yet to be tested prospectively.

Clinical trials of ICI in NSCLC

- Two PD-1 inhibitors, nivolumab and pembrolizumab, are approved in Europe for the treatment of advanced NSCLC, having shown clinical efficacy in a number of Phase I-III clinical trials.

- Atezolizumab is the first PD-L1 inhibitor to be approved for advanced NSCLC in the second-line setting following positive results in a Phase III trial versus docetaxel.

Potential clinical characteristics for guiding patient selection for single-agent anti-PD-1/PD-L1 therapy

- Clinical data were reviewed to assess the clinical utility of age, smoking status, tumor histology, performance status, presence of brain metastases, speed of disease progression, treatment history and mutational status in predicting the response to single-agent PD-1/PD-L1 inhibitors.

The use of single-agent anti-PD-1/PD-L1 therapies in clinically challenging populations

- The use of PD-1/PD-L1 inhibitors in patients with active autoimmune disease requiring systemic treatment is not recommended but should still be considered in those who have not experienced a flare-up of disease for 2 years and do not require immunosuppressive treatment.

- Due to the challenges associated with treating patients with impaired kidney or liver function with systemic cytotoxic drugs, anti-PD-1/PD-L1 agents may provide an alternative and safe treatment option for some of these patients.

Future perspective

- The validation of predictive markers for immunotherapy and the incorporation of routine testing into clinical practice would be an important step in targeting these drugs to patients most likely to benefit.

Conclusion

- Responses to PD-1/PD-L1 inhibitors have been observed in patients regardless of their age, smoking status, tumor histology or treatment history, so these factors should not be used for patient selection.

- The patients with untreated brain metastases, severe kidney or liver dysfunction, or active autoimmune disease requiring chronic systemic treatment should not receive PD-1/PD-L1 inhibitors, and those with targetable mutations should only receive these drugs once all other standard treatment options have failed. 
Financial \& competing interest disclosure

R Califano has received honoraria from AstraZeneca/Medimmune, Roche, MSD and BMS. R Lal has received honoraria from Eli Lilly, MSD, Pierre Fabre, Pfizer, Roche and AbbVie. C Lewanski has received honoraria and speaker fees from Roche and AstraZeneca. MC Nicolson has received advisory board and speaker honoraria from AstraZeneca/Medlmmune, Roche, MSD and BMS. CH Ottensmeier has received honoraria from AstraZeneca/Medlmmune, Roche and BMS. S Popat is a consultant to Ariad, AstraZeneca, BMS, Boehringer Ingelheim, Eli Lilly, Guardant Health, MSD, Novartis, Pfizer, Roche and Takeda. M Hodgson is an employee of Roche UK. PE Postmus has been an advisor to AbbVie, Astellas, AstraZeneca, BMS, Boehringer Ingelheim, Celgene, Clovis Oncology, G1 Therapeutics, Janssen, Merck Serono, MSD and Roche, received speaker fees from AstraZeneca, BMS, Boehringer Ingelheim, Eli Lilly and Pfizer, and received travel support from Boehringer Ingelheim, Celgene, Merck and Pfizer. The authors have no other relevant affiliations or financial involvement with any organization or entity with a financial interest in or financial conflict with the subject matter or materials discussed in the manuscript apart from those disclosed.

Medical writing support (including development of a draft outline and subsequent drafts in consultation with the authors, assembling tables and figures, collating author comments, copy editing, fact checking and referencing) was provided by A Wareham at Aspire Scientific (Bollington, UK), and funded by Roche Products Ltd (Welwyn Garden City, UK), in accordance with Good Publication Practice (GPP3) guidelines (www.ismpp.org/gpp3). This work was supported by Roche Products Ltd (Welwyn Garden City, UK). Employees of the sponsor were involved in the conception of the manuscript. All authors, including the author employed by the sponsor ( $\mathrm{M}$ Hodgson), participated in the analysis and interpretation of the data and in the development of the manuscript. The authors did not receive any compensation for the writing of the manuscript. The decision to submit for publication was that of the authors alone, and all authors were involved in this decision.

\section{Open access}

This work is licensed under the Attribution-NonCommercial-NoDerivatives 4.0 Unported License. To view a copy of this license, visit http://creativecommons.org/licenses/by-nc-nd/4.0/

\section{References}

Papers of special note have been highlighted as: $\bullet$ of interest; $\bullet \bullet$ of considerable interest

1. Malhotra J, Jabbour SK, Aisner J. Current state of immunotherapy for non-small cell lung cancer. Transl. Lung Cancer Res. 6(2), 196-211 (2017).

2. Hanna N, Johnson D, Temin S et al. Systemic therapy for stage IV non-small-cell lung cancer: American Society of Clinical Oncology clinical practice guideline update. J. Clin. Oncol. 33(30), 3488-3515 (2017).

3. NCCN Guideline Panel. National Comprehensive Cancer Network clinical practice guidelines in oncology. Non-Small Cell Lung Cancer Version 3.2018 (2018). www.nccn.org/professionals/physician_gls/pdf/nscl.pdf

4. Shukuya T, Carbone DP. Predictive markers for the efficacy of anti-PD-1/PD-L1 antibodies in lung cancer. J. Thorac. Oncol. 11(7), 976-988 (2016).

5. Kerr KM, Hirsch FR. Programmed death ligand-1 immunohistochemistry: friend or foe? Arch. Pathol. Lab. Med. 140(4), 326-331 (2016).

6. Mino-Kenudson M. Programmed cell death ligand-1 (PD-L1) expression by immunohistochemistry: could it be predictive and/or prognostic in non-small cell lung cancer? Cancer Biol. Med. 13(2), 157-170 (2016).

7. Kerr KM, Tsao MS, Nicholson AG, Yatabe Y, Wistuba II, Hirsch FR. Programmed death-ligand 1 immunohistochemistry in lung cancer: in what state is this art? J. Thorac. Oncol. 10(7), 985-989 (2015).

8. Cho JH, Sorensen SF, Choi Y-L et al. Programmed death ligand 1 expression in paired non-small cell lung cancer tumor samples. Clin. Lung Cancer 18(6), e473-e479 (2017).

9. McLaughlin J, Han G, Schalper KA et al. Quantitative assessment of the heterogeneity of PD-L1 expression in non-small-cell lung cancer. JAMA Oncol. 2(1), 46-54 (2016).

10. Nakamura S, Hayashi K, Imaoka Y et al. Intratumoral heterogeneity of programmed cell death ligand-1 expression is common in lung cancer. PLoS ONE 12(10), e0186192 (2017).

11. Topalian SL, Taube JM, Anders RA, Pardoll DM. Mechanism-driven biomarkers to guide immune checkpoint blockade in cancer therapy. Nat. Rev. Cancer 16(5), 275-287 (2016).

12. Diggs LP, Hsueh EC. Utility of PD-L1 immunohistochemistry assays for predicting PD-1/PD-L1 inhibitor response. Biomark. Res. 5(1), 12 (2017).

13. Cooper WA, Russell PA, Cherian M et al. Intra- and interobserver reproducibility assessment of PD-L1 biomarker in non-small cell lung cancer. Clin. Cancer Res. 23(16), 4569-4577 (2017). 
14. Scheerens $\mathrm{H}$, Malong A, Bassett $\mathrm{K}$ et al. Current status of companion and complementary diagnostics: strategic considerations for development and launch. Clin. Transl. Sci. 10(2), 84-92 (2017).

15. Gadgeel SM, Kowanetz M, Zou W et al. 1296O: clinical efficacy of atezolizumab in PD-L1 selected subgroups defined by SP142 and 22C3 IHC assays in 2L+ NSCLC: results from the randomized OAK trial. Ann. Oncol. 28(Suppl. 5), v460-v496 (2017).

16. Ratcliffe MJ, Sharpe A, Midha A et al. Agreement between programmed cell death ligand-1 diagnostic assays across multiple protein expression cutoffs in non-small cell lung cancer. Clin. Cancer Res. 23(14), 3585-3591 (2017).

17. Adam J, Le Strang N, Rouquette I et al. Multicenter harmonization study for PD-L1 IHC testing in non-small-cell lung cancer. Ann. Oncol. 29(4), 953-958 (2018).

18. Büttner R, Gosney JR, Skov BG et al. Programmed death-ligand 1 immunohistochemistry testing: a review of analytical assays and clinical implementation in non-small-cell lung cancer. J. Clin. Oncol. 35(34), 3867-3876 (2017).

19. Tsao M, Kerr K, Yatabe Y, Hirsch FR. PL03.03: Blueprint 2: PD-L1 immunohistochemistry comparability study in real-life, clinical samples. J. Thorac. Oncol. 12(11), S1606 (2017).

20. Hirsch FR, McElhinny A, Stanforth D et al. PD-L1 immunohistochemistry assays for lung cancer: results from Phase I of the Blueprint PD-L1 IHC assay comparison project. J. Thorac. Oncol. 12(2), 208-222 (2017).

21. Hirsch FR. PD-L1 IHC Blueprint project: ongoing progress toward consistency among assays (2018). www.lungcancernews.org/2018/04/05/pd-11-ihc-blueprint-project-ongoing-progress-toward-consistency-among-assays/

22. Stoy SP, Rosen L, Mueller J, Murgu S. Programmed death-ligand 1 testing of lung cancer cytology specimens obtained with bronchoscopy. Cancer Cytopathol. 126(2), 122-128 (2018).

23. Marius I, Jonathan J, Lingkang H, Veronique H, Shirin KF, Paul H. Use of the $22 \mathrm{C} 3$ anti-programmed death-ligand 1 antibody to determine programmed death-ligand 1 expression in cytology samples obtained from non-small cell lung cancer patients. Cancer Cytopathol. 126(4), 264-274 (2018).

24. Yarchoan M, Hopkins A, Jaffee EM. Tumor mutational burden and response rate to PD-1 inhibition. N. Engl. J. Med. 377(25), 2500-2501 (2017).

25. Rizvi NA, Hellmann MD, Snyder A et al. Cancer immunology. Mutational landscape determines sensitivity to PD-1 blockade in non-small cell lung cancer. Science 348(6230), 124-128 (2015).

-. Key study demonstrating the association between tumor mutational burden and neoantigen burden and the response to anti-PD-1 therapy in lung cancer.

26. Campesato LF, Barroso-Sousa R, Jimenez L et al. Comprehensive cancer-gene panels can be used to estimate mutational load and predict clinical benefit to PD-1 blockade in clinical practice. Oncotarget 6(33), 34221-34227 (2015).

27. Iwai Y, Hamanishi J, Chamoto K, Honjo T. Cancer immunotherapies targeting the PD-1 signaling pathway. J. Biomed. Sci. $24(1), 26$ (2017).

28. Carbone DP, Reck M, Paz-Ares L et al. First-line nivolumab in stage IV or recurrent non-small-cell lung cancer. $N$. Engl. J. Med. 376(25), 2415-2426 (2017).

- Phase III trial of nivolumab versus platinum-based chemotherapy in patients with PD-L1 positive ( $\geq 1 \%)$ non-small-cell lung cancer (NSCLC) in the first-line setting that demonstrated nivolumab was not associated with improved survival compared with chemotherapy.

29. Gettinger S, Choi J, Mani N et al. MA15.06 Predictive value of measuring somatic mutations and tumor infiltrating lymphocytes for PD-1 axis therapy in non-small cell lung cancer (NSCLC). J. Thorac. Oncol. 12(1), S430-S431 (2017).

30. Kowanetz M, Zou W, Shames D et al. OA20.01 tumor mutation burden (TMB) is associated with improved efficacy of atezolizumab in 1L and 2L+ NSCLC patients. J. Thorac. Oncol. 12(1), S321-S322 (2017).

31. Gandara DR, Kowanetz M, Mok TSK et al. 1295O: blood-based biomarkers for cancer immunotherapy: tumor mutational burden in blood (bTMB) is associated with improved atezolizumab efficacy in 2L+ NSCLC (POPLAR and OAK). Ann. Oncol. 28(Suppl. 5), v460-v496 (2017).

32. Rizvi H, Sanchez-Vega F, La K et al. Molecular determinants of response to anti-programmed cell death (PD)-1 and anti-programmed death-ligand 1 (PD-L1) blockade in patients with non-small-cell lung cancer profiled with targeted next-generation sequencing. J. Clin. Oncol. 36(7), 633-641 (2018).

33. Hellmann MD, Ciuleanu T-E, Pluzanski A et al. Nivolumab plus ipilimumab in lung cancer with a high tumor mutational burden. $N$. Engl. J. Med. 378, 2093-2104 (2018).

34. European Medicines Agency. Nivolumab summary of product characteristics (2018). www.ema.europa.eu/docs/en_GB/document_library/EPAR-Product_Information/human/003985/WC500189765.pdf

35. US FDA. Opdivo (nivolumab) prescribing information (2018). https://www.accessdata.fda.gov/drugsatfda_docs/label/2018/125554s048s049s050s051s052s061s062s064s065s066lbl.pdf

36. Borghaei H, Paz-Ares L, Horn L et al. Nivolumab versus docetaxel in advanced nonsquamous non-small-cell lung cancer. N. Engl. J. Med. 373(17), 1627-1639 (2015). 
- Pivotal Phase III trial in previously-treated patients with nonsquamous NSCLC that demonstrated nivolumab was associated with improved outcomes versus docetaxel.

37. Brahmer J, Reckamp KL, Baas $\mathrm{P}$ et al. Nivolumab versus docetaxel in advanced squamous-cell non-small-cell lung cancer. $N$. Engl. J. Med. 373(2), 123-135 (2015).

- Pivotal Phase III trial of nivolumab versus docetaxel in squamous NSCLC (with subgroup analysis) that demonstrated significantly improved suvival and response rates with nivolumab in previously-treated patients.

38. Gettinger S, Rizvi NA, Chow LQ et al. Nivolumab monotherapy for first-line treatment of advanced non-small-cell lung cancer. J. Clin Oncol. 34(25), 2980-2987 (2016).

39. Garon EB, Rizvi NA, Hui R et al. Pembrolizumab for the treatment of non-small-cell lung cancer. N. Engl. J. Med. 372(21), 2018-2028 (2015).

40. Herbst RS, Baas P, Kim D-W et al. Pembrolizumab versus docetaxel for previously treated, PD-L1-positive, advanced non-small-cell lung cancer (KEYNOTE-010): a randomised controlled trial. Lancet 387(10027), 1540-1550 (2016).

- Pivotal Phase II/III trial of pembrolizumab versus docetaxel in NSCLC that demonstrated pembrolizumab prolonged survival in PD-L1 (1\%)-positive patients.

41. Reck M, Rodríguez-Abreu D, Robinson AG et al. Pembrolizumab versus chemotherapy for PD-L1-positive non-small-cell lung cancer. N. Engl. J. Med. 375(19), 1823-1833 (2016).

- Phase III trial of pembrolizumab versus platinum-based chemotherapy in patients with PD-L1 positive ( $\geq 50 \%)$ NSCLC in the first-line setting that demonstrated significantly longer progression-free survival and overall survival in the pembrolizumab arm.

42. Peters S, Gettinger S, Johnson ML et al. Phase II trial of atezolizumab as first-line or subsequent therapy for patients with programmed death-ligand 1-selected advanced non-small-cell lung cancer (BIRCH). J. Clin. Oncol. 35(24), 2781-2789 (2017).

43. Fehrenbacher L, Spira A, Ballinger M et al. Atezolizumab versus docetaxel for patients with previously treated non-small-cell lung cancer (POPLAR): a multicentre, open-label, Phase II randomised controlled trial. Lancet 387(10030), 1837-1846 (2016).

44. Rittmeyer A, Barlesi F, Waterkamp D et al. Atezolizumab versus docetaxel in patients with previously treated non-small-cell lung cancer (OAK): a Phase III, open-label, multicentre randomised controlled trial. Lancet 389(10066), 255-265 (2017).

- First Phase III study to report results of a PD-L1 inhibitor. Atezolizumab demonstrated improvements in survival versus docetacel in previously-treated NSCLC patients.

45. Gulley JL, Rajan A, Spigel DR et al. Avelumab for patients with previously treated metastatic or recurrent non-small-cell lung cancer (JAVELIN Solid Tumor): dose-expansion cohort of a multicentre, open-label, Phase Ib trial. Lancet Oncol. 18(5), 599-610 (2017).

46. Antonia SJ, Villegas A, Daniel D et al. Durvalumab after chemoradiotherapy in stage III non-small-cell lung cancer. $N$. Engl. J. Med. 377, 1919-1929 (2017).

47. European Medicines Agency. Pembrolizumab summary of product charateristics (2018). www.ema.europa.eu/docs/en_GB/document_library/EPAR-Product_Information/human/003820/WC500190990.pdf

48. US FDA. Keytruda (pembrolizumab) prescribing information (2017). www.accessdata.fda.gov/drugsatfda_docs/label/2017/125514s031lbl.pdf

49. US FDA. Tecentriq (atezolizumab) prescribing information (2018). www.accessdata.fda.gov/drugsatfda_docs/label/2018/761034s005lbl.pdf

50. European Medicines Agency. European public assessment report: Tecentriq (atezolizumab) (2018). www.ema.europa.eu/docs/en_GB/document_library/EPAR-Product_Information/human/004143/WC500235778.pdf

51. Elias R, Karantanos T, Sira E, Hartshorn KL. Immunotherapy comes of age: immune aging \& checkpoint inhibitors. J. Geriatr. Oncol. 8(3), 229-235 (2017).

52. Torre LA, Siegel RL, Jemal A. Lung cancer statistics. In: Lung Cancer and Personalized Medicine, Torre LA, Siegel RL, Jemal A (Eds). Springer, Cham, Switzerland, 1-19 (2016).

53. Elias R, Giobbie-Hurder A, Rahma OE. Efficacy of PD-1 and PD-L1 inhibitors in older adults: a meta-analysis. J. Clin. Oncol. 35(Suppl.), doi:10.1200/JCO.2017.35.15_suppl.e21544 (2017).

54. Popat S, Ardizzoni A, Ciuleanu T et al. 1303PD: nivolumab in previously treated patients with metastatic squamous NSCLC: results of a European single-arm, Phase II trial (CheckMate 171) including patients aged $\geq 70$ years and with poor performance status. Ann. Oncol. 28(Suppl. 5), mdx380.006 (2017).

55. Spigel D, Schwartzberg L, Waterhouse D et al. P3.02c-026: is nivolumab safe and effective in elderly and PS2 patients with non-small cell lung cancer (NSCLC)? Results of CheckMate 153. J. Thorac. Oncol. 12(1), S1287-S1288 (2017).

56. Abdel-Rahman O. Smoking and EGFR status may predict outcomes of advanced NSCLC treated with PD-(L)1 inhibitors beyond first line: a meta-analysis. Clin. Respir. J. 12(5), 1809-1819 (2017).

57. Alexandrov LB, Nik-Zainal S, Wedge DC et al. Signatures of mutational processes in human cancer. Nature 500(7463), 415-421 (2013).

58. European Medicines Agency. Nintedanib summary of product charateristics (2017). www.ema.europa.eu/docs/en_GB/document_library/EPAR-Product_Information/human/002569/WC500179970.pdf 
59. Chan BA, Hughes BGM. Targeted therapy for non-small cell lung cancer: current standards and the promise of the future. Transl. Lung Cancer Res. 4(1), 36-54 (2015).

60. Gadgeel S, Ciardiello F, Rittmeyer A et al. PL04a.02: OAK, a randomized Phase III study of atezolizumab vs docetaxel in patients with advanced NSCLC: results from subgroup analyses. J. Thorac. Oncol. 12(1), S9-S10 (2017).

61. Vokes EE, Ready N, Felip E et al. Nivolumab versus docetaxel in previously treated advanced non-small cell lung cancer (CheckMate 017 and CheckMate 057): 3-year update and outcomes in patients with liver metastases. Ann. Oncol. 29(4), 959-965 (2018).

62. Herbst RS, Baas P, Kim D-W et al. Factors associated with better overall survival (OS) in patients with previously treated, PD-L1-expressing, advanced NSCLC: multivariate analysis of KEYNOTE-010. J. Clin. Oncol. 35(Suppl.), Abstract 9090 (2017).

63. Kobayashi H, Omori S, Nakashima K et al. Response to the treatment immediately before nivolumab monotherapy may predict clinical response to nivolumab in patients with non-small-cell lung cancer. Int. J. Clin. Oncol. 22(4), 690-697 (2017).

64. Igawa S, Sato Y, Ryuge S et al. Impact of PD-L1 expression in patients with surgically resected non-small-cell lung cancer. Oncology 92(5), 283-290 (2017).

65. Clinical Trials Database: NCT02733159. https://clinicaltrials.gov/ct2/show/NCT02733159

66. Clinical Trials Database: NCT03191786. https://clinicaltrials.gov/ct2/show/NCT03191786

67. Ali A, Goffin JR, Arnold A, Ellis PM. Survival of patients with non-small-cell lung cancer after a diagnosis of brain metastases. Curr. Oncol. 20(4), e300-e306 (2013).

68. Champiat S, Dercle L, Ammari $S$ et al. Hyperprogressive disease is a new pattern of progression in cancer patients treated by anti-PD-1/PD-L1. Clin. Cancer Res. 23(8), 1920-1928 (2017).

69. Ferrara R, Caramella C, Texier M et al. 1306PD Hyperprogressive disease (HPD) is frequent in non-small cell lung cancer (NSCLC) patients (pts) treated with anti PD1/PD-L1 monoclonal antibodies (IO). Ann. Oncol. 28(Suppl. 5), mdx380.009 (2017).

70. Kaderbhai CG, Richard C, Fumet JD et al. Response to first-line chemotherapy regimen to predict efficacy of nivolumab in lung cancer. J. Clin. Oncol. 35(Suppl.), doi:10.1200/JCO.2017.35.15_suppl.3026 (2017).

71. Peters S, Cappuzzo F, Horn L et al. OA03.05: Analysis of early survival in patients with advanced non-squamous NSCLC treated with nivolumab vs docetaxel in CheckMate 057. J. Thorac. Oncol. 12(1), S253 (2017).

72. Komdeur FL, Prins TM, van de Wall S et al. CD103+ tumor-infiltrating lymphocytes are tumor-reactive intraepithelial CD8+ T cells associated with prognostic benefit and therapy response in cervical cancer. Oncoimmunology 6(9), e1338230 (2017).

73. Gottfried M, Bennouna J, Bondarenko I et al. Efficacy and safety of nintedanib plus docetaxel in patients with advanced lung adenocarcinoma: complementary and exploratory analyses of the Phase III LUME-Lung 1 study. Target Oncol. 12(4), 475-485 (2017).

74. Shaverdian N, Lisberg AE, Bornazyan K et al. Previous radiotherapy and the clinical activity and toxicity of pembrolizumab in the treatment of non-small-cell lung cancer: a secondary analysis of the KEYNOTE-001 Phase I trial. Lancet Oncol. 18(7), 895-903 (2017).

75. Jain P, Khunger M, Pasupuleti V, Hernandez AV, Velcheti V. Efficacy of PD-1/PD-L1 inhibitors in the front-line setting as compared to previously treated patients. J. Clin. Oncol. 35(Suppl.), doi:10.1200/JCO.2017.35.15_suppl.e20646 (2017).

76. Black RC, Khurshid H. NSCLC: an update of driver mutations, their role in pathogenesis and clinical significance. R. I. Med. J. (2013) 98(10), 25-28 (2015).

77. Vogelstein B, Papadopoulos N, Velculescu VE, Zhou S, Diaz LA, Kinzler KW. Cancer genome landscapes. Science 339(6127), 1546-1558 (2013).

78. Lee CK, Man J, Lord S et al. Checkpoint inhibitors in metastatic EGFR-mutated non-small cell lung cancer: a meta-analysis. J. Thorac. Oncol. 12(2), 403-407 (2017).

79. Gainor JF, Shaw AT, Sequist LV et al. EGFR mutations and ALK rearrangements are associated with low response rates to PD-1 pathway blockade in non-small cell lung cancer: a retrospective analysis. Clin. Cancer Res. 22(18), 4585-4593 (2016).

80. Kempf E, Rousseau B, Besse B, Paz-Ares L. KRAS oncogene in lung cancer: focus on molecularly driven clinical trials. Eur. Respir. Rev. 25(139), 71-76 (2016).

81. Kim JH, Kim HS, Kim BJ. Prognostic value of KRAS mutation in advanced non-small-cell lung cancer treated with immune checkpoint inhibitors: a meta-analysis and review. Oncotarget 8(29), 48248-48252 (2017).

82. Reungwetwattana T, Liang Y, Zhu V, Ou SI. The race to target MET exon 14 skipping alterations in non-small cell lung cancer: the why, the how, the who, the unknown, and the inevitable. Lung Cancer 103, 27-37 (2017).

83. Sabari JK, Montecalvo J, Chen R et al. PD-L1 expression and response to immunotherapy in patients with MET exon 14-altered non-small cell lung cancers (NSCLC). J. Clin. Oncol. 35(Suppl. 15), 8512-8512 (2017).

84. Schrock AB, Frampton GM, Suh J et al. Characterization of 298 patients with lung cancer harboring MET exon 14 skipping alterations. J. Thorac. Oncol. 11(9), 1493-1502 (2016).

85. Schrock A, Sharma N, Peled N et al. MA14.01 Updated dataset assessing tumor mutation burden (TMB) as a biomarker for response to PD-1/PD-L1 targeted therapies in lung cancer (LC). J. Thorac. Oncol. 12(1), S422 (2017). 
86. Dudnik E, Peled N, Nechushtan H et al. BRAF mutant lung cancer: PD-L1 expression, tumor mutational burden, microsatellite instability status and response to immune check-point inhibitors. J. Thorac. Oncol. 13(8), 1128-1137 (2018).

87. Khan SA, Pruitt SL, Xuan L, Gerber DE. Prevalence of autoimmune disease among patients with lung cancer: implications for immunotherapy treatment options. JAMA Oncol. 2(11), 1507-1508 (2016).

88. Leonardi GC, Gainor JF, Azimi RS et al. Use of PD-1 pathway inhibitors among patients with non-small cell lung cancer (NSCLC) and preexisting autoimmune disorders. J. Clin. Oncol. 35(Suppl.), Abstract 9081 (2017).

89. Abdel-Wahab N, Shah M, Lopez-Olivo MA, Suarez-Almazor ME. Use of immune checkpoint inhibitors in the treatment of patients with cancer and preexisting autoimmune disease: a systematic review. Ann. Intern. Med. 168(2), 121-130 (2018).

90. Menzies AM, Johnson DB, Ramanujam S et al. Anti-PD-1 therapy in patients with advanced melanoma and preexisting autoimmune disorders or major toxicity with ipilimumab. Ann. Oncol. 28(2), 368-376 (2017).

91. Herz S, Hofer T, Papapanagiotou M et al. Checkpoint inhibitors in chronic kidney failure and an organ transplant recipient. Eur. J. Cancer 67, 66-72 (2016).

92. Kanz BA, Pollack MH, Johnpulle R et al. Safety and efficacy of anti-PD-1 in patients with baseline cardiac, renal, or hepatic dysfunction. J. Immunother. Cancer 4, 60 (2016).

93. Ryman JT, Meibohm B. Pharmacokinetics of monoclonal antibodies. CPT Pharmacometrics Syst. Pharmacol. 6(9), 576-588 (2017).

94. He J, Hu Y, Hu M, Li B. Development of PD-1/PD-L1 pathway in tumor immune microenvironment and treatment for non-small cell lung cancer. Sci. Rep. 5, 13110 (2015).

95. Goodman AM, Kato S, Bazhenova L et al. Tumor mutational burden as an independent predictor of response to immunotherapy in diverse cancers. Mol. Cancer Ther. 16(11), 2598-2608 (2017).

96. Kowanetz M, Zou W, McCleland M et al. MA 05.09: pre-existing immunity measured by teff gene expression in tumor tissue is associated with atezolizumad efficacy in NSCLC. J. Thorac. Oncol. 12(11), S1817-S1818 (2017).

97. Bagley SJ, Kothari S, Aggarwal C et al. Pretreatment neutrophil-to-lymphocyte ratio as a marker of outcomes in nivolumab-treated patients with advanced non-small-cell lung cancer. Lung Cancer 106, 1-7 (2017).

98. Mouw KW, Goldberg MS, Konstantinopoulos PA, D’Andrea AD. DNA damage and repair biomarkers of immunotherapy response. Cancer Discov. 7(7), 675-693 (2017).

99. Le DT, Durham JN, Smith KN et al. Mismatch-repair deficiency predicts response of solid tumors to PD-1 blockade. Science 357(6349), 409-413 (2017).

100. US FDA. FDA grants accelerated approval to pembrolizumab for first tissue/site agnostic indication (2017). www.fda.gov/Drugs/InformationOnDrugs/ApprovedDrugs/ucm560040.htm

101. Chae YK, Anker JF, Bais P, Namburi S, Giles FJ, Chuang JH. Mutations in DNA repair genes are associated with increased neo-antigen load and activated T cell infiltration in lung adenocarcinoma. Oncotarget 9(8), 7949-7960 (2018).

102. Karasaki T, Nagayama K, Kuwano $\mathrm{H}$ et al. An immunogram for the cancer-immunity cycle: towards personalized immunotherapy of lung cancer. J. Thorac. Oncol. 12(5), 791-803 (2017).

103. Blank CU, Haanen JB, Ribas A, Schumacher TN. The 'cancer immunogram'. Science 352(6286), 658-660 (2016).

104. Lee CK, Man J, Lord S et al. Clinical and molecular characteristics associated with survival among patients treated with checkpoint inhibitors for advanced non-small cell lung carcinoma: a systematic review and meta-analysis. JAMA Oncol. 4(2), 210-216 (2018). 
